\title{
CAPITAL SOCIAL: EXPLORANDO A REDE DE RELAÇÕES DA EMPRESA
}

RESUMO

As organizações operam hoje em um mundo de crescente complexidade em que o conhecimento, em constante evolução, põe em evidência a necessidade de se buscar informação fora dos limites fronteiriços formais. Sendo assim, grandes quantidades de conhecimento são adquiridas de fontes externas, processo consumado quando as organizações estendem seus vínculos a organizações e indivíduos de fora.

Esse artigo explora métodos para se ter acesso a este conhecimento que extrapola as fronteiras da empresa, bem como os modos mais eficientes de se aproveitar este, que é o capital social das organizações. Isso inclui a importância de se monitorar continuamente a qualidade do conhecimento advindo dessas fontes, atentando sempre para o risco de que os relacionamentos transformem-se em sujeição. O presente artigo detalha ainda as várias formas de evitar tais armadilhas.

\section{Vikas Anand}

Ph.D. pela Arizona State University e Professor-Assistente na University of Arkansas.

E-mail: vikas@walton.uark.edu

\section{William H. Glick}

Ph.D. pela University of Califórnia

E-mail: biu.glick@asu.edu

\section{Charles C. Manz}

Professor Titular na University of Massachusetts e Consultor.

E-mail: cmanz@s.m.umass.edu

\begin{abstract}
Organizations are operating in an increasingly complex world, where knowledge is continuously changing, requiring them to apply large amounts of information. Accordingly, they need to source large amounts of knowledge from outside the organization, a process that is accomplished when organizations tap their linkages to external organizations and individuals.

This article explores a variety of methods that can be used to access knowledge that lies outside the organization's boundaries, such as how to take advantage of social capital. Additionally, as organizations develop their relationships with external entities they also need to continuously monitor the quality of knowledge derived from such sources; there is always the danger of such relationships becoming a liability without the organization being aware of it. This paper details the various ways through which such pitfalls may be avoided.
\end{abstract}

PALAVRAS-CHAVE Conhecimento externo, estratégia, capital social, gestão de conhecimento, fronteiras da organização KEY WORDS External knowledge, strategy, social capital, knowledge management, organization's boundaries. 


\section{PROSPERANDO COM BASE NO CONHECIMENTO DE PESSOAL EXTERNO: A EXTENSÃO DO CAPITAL SOCIAL DA ORGANIZAÇÃO}

Jim Campbell estava imerso em pensamentos profundos enquanto desenvolvia o tema da palestra central que faria na apresentação sobre alta tecnologia na semana seguinte $^{1}$. Era uma honra inesperada ser convidado para discursar. Ele era o CEO de uma empresa de médio porte em um campo tradicionalmente dominado por gigantes. E ainda havia sido escolhido devido ao que os organizadores classificaram como "destacada liderança em conhecimento de sua indústria". Eles haviam sugerido que se concentrasse no segredo do sucesso de sua empresa... O que levou a companhia ao relevante sucesso em uma indústria de intenso conhecimento? Como ele havia desenvolvido o conhecimento intensivo que colocou sua empresa muito à frente das corporações que se vangloriavam de contar com exércitos de cientistas? Ele refletiu sobre sua empresa. Contava com bons funcionários, entre os melhores da indústria. No entanto, eles estavam em muito menor número do que os da concorrência. E Jim não podia dizer honestamente que as habilidades de seus funcionários não eram superadas pelas de seus concorrentes. Como, então, ele havia desenvolvido a liderança em conhecimento que sua empresa exemplificava? "Utilizamos o conhecimento de pessoas de fora", disse, digitando freneticamente no teclado de seu computador. É assim que ele havia feito. E esse seria o tema de sua palestra.

Administrar conhecimento é a chave do sucesso organizacional. No mundo competitivo de hoje, as fontes tradicionais de vantagem competitiva tornaram-se menos relevantes. A vantagem organizacional raramente é fruto de tecnologias superiores, de distribuição eficiente ou outras atividades da cadeia de valor. Robin Cooper (1995) argumentou de modo convincente que a vantagem competitiva que advém de qualquer recurso organizacional específico será momentânea. Nesta era de intensa concorrência, os competidores irão neutralizar qualquer vantagem competitiva em um espaço de tempo muito curto. Assim, é mais provável que a vantagem competitiva nasça do conhecimento que a organização aplica às suas atividades críticas (Grant, 1996).

Apesar de uma importante etapa para enfrentar o desafio dos ambientes de conhecimento de hoje envolver o incremento da perícia dos funcionários, as empresas estão concluindo que a cada dia elas precisam recorrer mais ao conhecimento de agentes externos à organização para atender a suas exigências de conhecimento. $\mathrm{O}$ capital social da organização refere-se ao conhecimento e à informação aos quais as organizações podem ter acesso, utilizando suas conexões formais e informais com agentes externos - como clientes, mão-de-obra terceirizada de outras organizações e assim por diante ${ }^{2}$.

No entanto, a despeito de sua importância, muitas organizações não têm capacidade de tirar vantagem do capital social por inúmeras razões. Em alguns casos, os gerentes podem desconsiderar o conhecimento e a informação que vêm de fora da organização porque tal conhecimento não seria consistente com suas visões de mundo (MacDonald, 1995). Em outros casos, os gerentes podem não ter a capacidade de utilizar seu capital social porque tentam tirar proveito dele da maneira errada. Eles podem, por exemplo, utilizar um meio de comunicação que não seja adequado ao conteúdo que estão tentando obter (Anand, Manz e Glick, 1998). Em outros casos ainda, as organizações podem não ter a capacidade de tirar proveito de seu capital social porque não contam com as redes sociais adequadas. Por causa da crescente importância do conhecimento e das fontes a ele relacionadas, as organizações que conseguem tirar proveito de seu capital social de modo mais efetivo conquistam uma significativa vantagem em relação à concorrência.

A discussão anterior levanta várias questões para as organizações. Como uma empresa pode controlar e utilizar melhor seu capital social? Que ações específicas os gerentes devem adotar para assegurarem que seus funcionários estejam motivados para tirar proveito do capital social? Quais são os diferentes modos pelos quais o capital social pode ser utilizado e que tipo de fontes de conhecimento devem ser utilizadas em condições específicas? Abordamos tais questões neste artigo e explicamos como os gerentes podem implementar sistemas e práticas que permitam às suas organizações se beneficiarem continuamente de seu capital social.

\section{CONHECIMENTO NO CONTEXTO DAS ORGANIZAÇÕES}

Iniciamos este artigo explicando os termos-chave que são relevantes para nossa argumentação. Em primeiro lugar, definimos conhecimento organizacional como qualquer informação, crença ou capacitação que a organização possa aplicar às suas atividades. O conhecimento foi definido na literatura de várias formas. Nonaka e Takeuchi (1995), seguindo a linha de Polanyi (1966), referem-se a ele como "crença verdadeira justificada". 
Nelson e Winter (1982) vêem-no como rotinas que podem existir nos níveis individual, do grupo e organizacional. Argote e Ingram (2000) avaliaram o conhecimento de modo a sugerir que ele consiste em habilidades e competências. Utilizamos uma distinção ampla e abrangente de conhecimento que inclui todos esses aspectos. Este pode existir de múltiplas formas: pode se referir ao conhecimento científico que o departamento de pesquisa de uma organização possui, ou informações sobre mercado externo, ou ainda capacidades que permitam aos gerentes tomar decisões efetivas nos ambientes em rápida mutação.

Historicamente, o conhecimento é categorizado em dois tipos: explícito e tácito (Polanyi, 1966) - hoje, aceita-se essa categorização como uma distinção crucial pelos teóricos do gerenciamento. O conhecimento explícito é aquele que pode ser facilmente comunicado e compartilhado pelos e entre os indivíduos - por exemplo, informações sobre o tamanho do mercado e legislação em um mercado externo que possam ser concretamente transferidas para um relatório, e que este possa ser compartilhado dentro da organização. O conhecimento tácito, por outro lado, é difícil de ser comunicado. Considere, por exemplo, um engenheiro de controle de qualidade que, em função dos anos de experiência, pode identificar a qualidade de um mecanismo recém-fabricado por meio dos sons e vibrações que emite na máquina de testes. Tal conhecimento não pode ser transferido utilizando-se um documento redigido e, ainda assim, é muito importante para a organização. A diferença entre conhecimento tácito e explícito é importante porque a escolha do método para o aproveitamento do capital social depende do tipo de conhecimento que se está buscando.

Uma parcela muito grande do conhecimento de uma organização reside dentro de seus limites formais - é o chamado conhecimento interno (Anand, Manz e Glick, 1998). No entanto, as organizações freqüentemente utilizam conhecimento que não reside dentro de seus limites formais - é o chamado conhecimento externo, que pode assumir uma variedade de formas. Por exemplo, as empresas podem entrar em contato com um consultor para obter conhecimento sobre um novo mercado no qual estão planejando ingressar. Uma outra opção é o CEO aconselhar-se informalmente com um colega do ramo bancário sobre o impacto de novas regulamentações federais, e assim por diante.

O capital social é o meio básico pelo qual as organizações importam conhecimento externo para a empresa. Apesar de não diretamente relacionado ao conhecimento interno, o conhecimento externo obtido por meio do capital social de uma organização gera impacto sobre o conhecimento interno de duas formas (Anand, Manz e Glick, 1998; MacDonald, 1995; Nonaka, 1995). Em primeiro lugar, à medida que o novo conhecimento externo ingressa na empresa, ele pode ser combinado ao conhecimento interno que já existe na corporação para gerar novas idéias. Em segundo lugar, uma comparação entre os conhecimentos externo e interno pode trazer à tona inconsistências que podem ajudar a identificar fraquezas ou incoerências do conhecimento interno já existente na empresa. Assim, o capital social gera impacto direto sobre o conhecimento externo da empresa e, indiretamente, gera impacto também sobre o interno. Além disso, devemos indicar que o tipo de conhecimento que uma empresa armazena internamente determina os benefícios que ela pode obter do capital social.

\section{A CRESCENTE IMPORTÂNCIA DO CAPITAL SOCIAL}

Jim Campbell deu uma olhada na enorme platéia. Sua palestra havia começado bem. Eles o estavam ouvindo atentamente. Ele prosseguiu: "Quando começamos com a NIT Technologies, ninguém nos deu chance de sobrevivência. Francamente, também tínhamos nossas dúvidas. Aqui estávamos nós, recém-iniciados e insignificantes em uma indústria de tecnologia extremamente sofisticada. Precisávamos de enormes quantidades de conhecimento técnico avançado e capacitação. Nossos 18 cientistas tinham de igualar o conhecimento das grandes corporações - algumas das quais contavam com centenas de cientistas". Jim fez uma pausa de efeito. "A base para o sucesso da NIT foi lançada quando percebemos que não podíamos, e não devíamos, igualar-nos ao conhecimento de nossa concorrência. Pelo menos não no sentido de possuir pessoalmente tal conhecimento. Em vez disso, concentramo-nos em utilizar o conhecimento que não possuíamos. Voltamo-nos para nossos fornecedores, clientes, amigos em outras organizações... Todos que nós soubéssemos que pudessem ser úteis, e os tornamos nossos parceiros do conhecimento. Nosso conhecimento foi somado ao deles à medida que embarcávamos em nossa jornada... (Leibiskind, Oliver, Zucker e Brewer, 1996).

O primeiro passo no aproveitamento do capital social exige que os gerentes reconheçam e compreendam seu crescente papel nos ambientes de hoje. Vários fatores contribuem para isso. Em primeiro lugar, nos ambientes de negócios atuais, os gerentes enfrentam uma cres- 
cente "densidade de conhecimento" - o que diz respeito à quantidade de conhecimento que deve ser aplicada a cada decisão organizacional. As tendências atuais rumo à globalização, a rápida mudança tecnológica e a pressão intensificada da concorrência vêm aumentando de modo significativo os volumes de conhecimento que os gerentes devem levar em consideração (Hitt, Keats e Demarie, 1998). Ao mesmo tempo, as organizações estão a cada dia tornando-se mais enxutas - isto é, reduzindo o número de gerentes na organização. Como resultado, menos gerentes trabalham com quantidades maiores de conhecimento - elevando, conseqüentemente, a densidade necessária de conhecimento. Por isso, é provável que as organizações possuam quantidades menores do conhecimento necessário dentro de suas fronteiras e que necessitem cada vez mais tirar proveito de seu capital social para realizar suas atividades.

Em segundo lugar, o conhecimento e as experiências passadas dos funcionários da organização são menos úteis hoje porque as empresas estão, a cada dia mais, enfrentando situações novas e inesperadas (Hitt e Reed, 2000). De modo a obter o conhecimento relevante a essas situações, as organizações freqüentemente precisam recorrer a seu conhecimento externo. Além disso, as companhias precisam adotar uma abordagem empresarial na qual equilibrem esforços para desenvolver e incrementar as atuais linhas de negócios, enquanto desenvolvem simultaneamente novos e inexplorados rumos (Eisenhardt, Brown e Neck, 2000). Como as empresas raramente contam com conhecimento "enlatado" para tal abordagem, geralmente precisam depender de seu capital social para conduzi-las pelas novas linhas de negócios.

Em terceiro lugar, o capital social torna-se extremamente importante nas indústrias emergentes de alta tecnologia, onde o conhecimento está sendo gerado rapidamente e distribuído de modo desigual entre várias pequenas corporações. Para as empresas sobreviverem nessas indústrias, precisam depender do conhecimento das outras e serem capazes de utilizá-lo. Por exemplo, um recente estudo (Deeds, Decarolis e Coombs, 1999) constatou que os cientistas e pesquisadores que trabalham em universidades e em organizações governamentais possuíam conhecimento relevante para a indústria de biotecnologia. As empresas bem sucedidas eram aquelas em que os cientistas podiam entrar em contato com tais especialistas para se aconselharem e obter ajuda no desenvolvimento de produtos-chave. Os funcionários das empresas de sucesso eram mais propensos a trocar informações com seus colegas de outras empresas.

\section{CONTROLE E USO DO CAPITAL SOCIAL}

Apesar de haver inúmeras fontes e métodos de aproveitamento do capital social, eles podem ser categorizados com base na natureza do conhecimento explícito versus tácito - e no volume de conhecimento que se está buscando. Exemplos de tais fontes e tipos de conhecimento obtido a partir delas são mostrados na Figura 1. O conhecimento explícito pode ser obtido a partir de fontes externas mediante o uso de meios de comunicação impessoais, como o intercâmbio eletrônico de dados, bem como por meio de fax e carta. O conhecimento tácito, por sua vez, exige meios de comunicação pessoais que permitam a interação direta e intensa entre os indivíduos (Daft e Lengel, 1986).

Do mesmo modo, o volume de conhecimento que se está buscando também influencia o modo como as organizações devem tirar proveito de seu capital social. Por exemplo, quando uma empresa busca a opinião de um perito em assuntos legais, a quantidade relativamente pequena de conhecimento externo pode ser facilmente usufruída por meio de uma rápida reunião. Entretanto, quando uma empresa está confiando em outra empresa para fornecer tecnologias-chave envolvidas na fabricação de um novo produto, mecanismos mais elaborados precisam ser estabelecidos para que o conhecimento necessário possa ser obtido. Cada um de seus quatro tipos é discutido a seguir.

\section{Obtenção de pequenos volumes de conhecimento explícito}

Jim Campbell lançou um rápido olhar para seus ouvintes e continuou: "Á medida que buscávamos formas de usufruir o capital social, concluímos que muitos de nossos funcionários eram membros de diferentes comunidades. As comunidades a que me refiro são agrupamentos informais de indivíduos, que gostam de trabalhar em áreas especializadas. Assim, temos uma comunidade de engenheiros que trabalham com IA (inteligência artificial), uma comunidade de pessoas que trabalham no desenvolvimento de firewalls, e assim por diante. Apesar de, na maioria dos casos, essas comunidades não constituírem organizações formais, percebemos que os indivíduos dentro delas mantêm fortes laços, mesmo quando não se conhecem. Algumas comunidades desenvolveram grupos de discussão on-line, por meio dos quais seus membros buscam e obtêm respostas para os problemas que enfrentam em seu trabalho. Vimos um grande potencial nessas comunidades e encorajamos nossos funcionários a tomar parte nelas. Por 
vezes provemos os recursos para nossos funcionários lançarem boletins eletrônicos ou grupos de discussão on-line, o que facilitou o desenvolvimento de várias comunidades. O envolvimento de nossos funcionários em tais comunidades nos tem fornecido informações de valor incalculável, de uma forma bastante oportuna" (Brown e Duguid, 1996; Schein, 1996).

Pequenos volumes de conhecimento explícito são freqüentemente necessários para solucionar problemas moderadamente estruturados que exigem pequenas quantidades de informação relativamente factual, recomendações de procedimentos, soluções diversificadas ou novos conceitos para repensar o problema. Quando se buscam pequenos volumes de conhecimento explícito, relatórios de rotina, cartas etc. podem resolver (Anand, Manz e Glick, 1998; Daft e Huber, 1987). Informações básicas podem ser obtidas quando os funcionários participam de encontros profissionais e técnicos. Publicações e periódicos técnicos são outras fontes de informação. No entanto, um meio básico de obter tal conhecimento é mediante o uso de redes sociais de funcionários - os vínculos e relacionamentos dos funcionários com outros indivíduos.

Por exemplo, em um estudo da indústria farmacêutica, os pesquisadores constataram que cientistas de várias corporações encontravam-se socialmente com frequência e discutiam abertamente questões relacionadas à pesquisa. Um conhecimento crítico era obtido e compartilhado nesse processo (Leibiskind, Oliver, Zucker e Brewer, 1996). Em uma direção semelhante, outro estudo constatou que os engenheiros de software freqüentemente buscavam soluções relacionadas a problemas no trabalho em meio a conversas com colegas de outras empresas. Esse modo de compartilhar conhecimento ocorre especialmente em indústrias nas quais os funcionários mantêm fortes laços e identificam-se mais com suas profissões do que com a organização (Schein, 1996). Apesar de algumas organizações reprovarem esse tipo de partilha, qualquer exposição de conhecimento que seja propriedade de uma empresa é geralmente compensada pela aquisição de novo conhecimento durante essas trocas sociais informais.

De modo a facilitar que o conhecimento construtivo seja compartilhado desse modo, as organizações podem ajudar patrocinando associações profissionais e encorajando seus funcionários a se envolverem nelas. Também podem patrocinar eventos especiais, como almoços de profissionais ou séries de palestras, que congreguem funcionários de várias empresas em sua indústria. $\mathrm{Ou}$, como no exemplo no início desta seção, podem encorajar seus funcionários a fazerem parte de comunidades de trabalhadores.

As organizações também têm a chance de obter informações valiosas de parceiros e investidores, como clien-

Figura 1 - Métodos apropriados para 0 aproveitamento do capital social

\section{Intercâmbio eletrônico de informações entre as organizações (p. ex., EDI e XML)}

Alto

\section{Volume de conhecimento necessário}

Exemplos de tipo de conhecimento buscado: relatórios de crédito sobre amostras de consumidores-alvo; comportamento/satisfação do consumidor no ponto de venda do varejo (em empresas de produtos de consumo); etc.

\section{Alianças estratégicas}

Exemplos de conhecimento aproveitado: experiência para desenhar, produzir e promover produtos no mercado em um novo país; conhecimento necessário para desenvolver tecnologia nova e revolucionária ( $p$. ex., tecnologia de DVD); etc.

Aproveitamento dos parceiros e investidores da organização, equipes interorganizacionais, encaixe de especialistas na organização (consultores e especialistas contingenciais).

Exemplos de conhecimento aproveitado: reação provável do governo à proposta de fusão de grandes empresas, adequação de novo design de produto, opiniões legais etc.
Explícito
Tipo de conhecimento
Tácito
Exemplos de conhecimento aproveitado: crescimento no volume de vendas da concorrência, novas promoções de vendas sendo lançadas pela concorrência etc.

Contatos sociais informais (conversas por telefone, e-mail etc.), relatórios, publicações técnicas etc.

Baixo 
tes e fornecedores. Um recente estudo sobre a indústria de software, por exemplo, concluiu que as empresas apresentavam taxas de crescimento mais altas quando sua alta administração, no momento de tomar decisões estratégicas, buscava grandes quantidades de informação junto a seus clientes e fornecedores (Anand, 1998). A despeito da intensa concorrência e das tentativas de manter segredo sobre novos produtos, empresas como a Netscape e a Microsoft envolvem ativamente seus clientes mais sofisticados em repetidos "testes beta" para verificar as reações dos clientes e obter retorno. Outras empresas, como a Toyota, tratam os fornecedores como parceiros, e investem dinheiro na melhoria das instalações dos fornecedores ou no treinamento de seus funcionários. Tais ações motivam os parceiros e investidores a compartilharem informações de modo proativo com a empresa, dando a ela, desse modo, vantagem competitiva no mercado.

Ainda que os parceiros, investidores e contatos sociais dos gerentes possam fornecer pequenas quantidades de conhecimento explícito informalmente, esse processo não é adequado à obtenção de conhecimento tácito ou mesmo para grandes quantidades de conhecimento explícito. A obtenção de conhecimento tácito exige interações mais intensas, e pedidos informais por informação são ineficazes. De modo similar, à medida que o volume de conhecimento necessário aumenta, é mais eficiente para as organizações instituir sistemas e procedimentos que cumpram essa tarefa: na ausência de tais procedimentos, os gerentes podem despender quantidades muito maiores de tempo na obtenção das informações necessárias.

\section{Obtenção de pequenos \\ volumes de conhecimento tácito}

Os gerentes que enfrentam problemas de mau estruturamento, com alta ambigüidade sobre causas e efeitos, necessitam de mais conhecimento tácito, como aconselhamento legal, depuração de códigos de software, desenvolvimento de um novo plano de negócios e transferências das melhores práticas de indústrias correlatas. A obtenção de pequenos volumes de conhecimento tácito geralmente exige o envolvimento direto de especialistas-chave em trocas altamente interativas.

Quando as empresas precisam importar conhecimento tácito em um número limitado de domínios, elas podem utilizar vários métodos. Podem absorver especialistas na unidade organizacional que necessita do conhecimento - por exemplo, consultores, especialistas contingenciais, ou utilizar funcionários de outras empresas como membros de equipes de projetos organizacionais. Também podem desenvolver mecanismos para obter conhecimento tácito junto a parceiros e investidores. Descreveremos rapidamente cada um desses métodos a seguir.

\section{Consultores e especialistas contingenciais}

Consultores podem ajudar fornecendo conhecimento de dois modos críticos. Em primeiro lugar, considerando que o conhecimento é a matéria-prima básica de muitas empresas de consultoria, eles concentram-se na obtenção do melhor conhecimento a custos competitivos. Em segundo lugar, já que a maioria dos consultores trabalha com várias empresas, representando diferentes indústrias, eles podem atuar como agentes de transferência de conhecimento. Para ilustrar, considere o recente estudo de uma empresa de consultoria que trabalhava com clientes de indústrias tão diferentes quanto brinquedos, produtos químicos, elétricos e semicondutores. O maior sucesso dessa empresa aconteceu quando ela adotou o aprendizado conquistado no trabalho com a indústria de brinquedos para solucionar problemas específicos da indústria de semicondutores (Hargadon e Sutton, 1997).

Outra interessante fonte de conhecimento externo está crescendo rapidamente: os especialistas contingenciais. Especialmente em indústrias de alta tecnologia, as empresas vêem-se freqüentemente enfrentando a necessidade de conhecimento muito específico, que só é necessário por um curto período de tempo. Em vez de gastar dinheiro com o treinamento de seus próprios funcionários para que eles apreendam tal conhecimento, muitas organizações preferem contratar temporariamente especialistas para cumprir um contrato de trabalho por um período específico. Essa tendência está ganhando destaque especialmente na indústria de software, na qual os trabalhadores contingenciais atuam em projetos tão diversos quanto a solução do bug do milênio, a adaptação de software de Planejamento de Recursos de Empreendimento (Enterprise Resource Planning - ERP) para clientes residentes e o desenvolvimento de software para microchips.

A utilização de especialistas contingenciais traz benefícios óbvios para as empresas. Por exemplo, as empresas ganham acesso a conhecimento especializado sem ter de ampliar sua força de trabalho, além da oportunidade de buscar os indivíduos com melhores níveis de conhecimento para executar o trabalho. A utilização de especialistas contingenciais é benéfica quando a tarefa que eles recebem é relativamente independente das atividades típicas da organização. Além do mais, considerando que a organização tem menos controle sobre a execução de tais tarefas, o trabalho deve permitir que os 
resultados desejados sejam claramente especificados.

A despeito das inúmeras vantagens de se utilizarem especialistas contingenciais, há também os revezes. Especialistas contingenciais podem aprender as práticas organizacionais e disseminá-las para o cliente seguinte, revelando, desse modo, segredos de mercado à concorrência. Também existe a possibilidade de que esses indivíduos apresentem moral e comprometimento mais baixos para com a organização, dado o caráter temporário de seu trabalho (Feldman e Turnley, 1994; Kochan e Smith, 1992). Em uma entrevista com os autores, um especialista contingencial que trabalhou em um projeto de software para uma das cem empresas listadas pela revista Fortune relatou-nos o seguinte:

"Nos últimos dois anos trabalhei em empresas em Phoenix, Los Angeles e Dakota do Sul... Acaba ficando cansativo. Trabalho aqui, cercado por funcionários... e sei que não sou um deles. Somos tratados como forasteiros, e é isso o que somos... É difícil comprometer-se com qualquer coisa além das especificações do produto [que a empresa forneceu]. Houve momentos em que percebi que podia melhorar as especificações... mas então [eu não fiz isso porque] não valia a pena".

Nosso trabalho inicial com especialistas contingenciais sugere que a falta de motivação pode tornar-se um grande problema se as organizações não se esforçarem o suficiente para integrar melhor esses trabalhadores. Sendo assim, tais abordagens devem ser utilizadas com cautela.

\section{Redes organizacionais de parceiros e investidores}

As organizações podem alcançar bons resultados trabalhando com seus parceiros e investidores para obter conhecimento limitado a uns poucos domínios. Se o conhecimento buscado for tácito, métodos de comunicação comuns têm menor possibilidade de transferir conhecimento com eficácia. Em vez disso, as organizações precisam identificar métodos criativos para usufruir o conhecimento.

Os distribuidores da Caterpillar, por exemplo, estão sempre envolvidos em todas as decisões relacionadas às suas áreas (Fites, 1996). Os distribuidores tomam parte normalmente nas equipes decisórias da Caterpillar, e suas idéias são valorizadas. A Toyota envolve rotineiramente funcionários de seus fornecedores em suas equipes de desenvolvimento de produto (Lincoln, Ahmedjian e Mason, 1998). Em ambos os casos, o conhecimento tácito de pessoas de fora é disponibilizado para a Caterpillar e a Toyota. A Hitachi adotou uma prática interessante, chamada Shukko, que envolve a transferência de funcio- nários para trabalhar com clientes e fornecedores por um período de três a seis meses (Lincoln, Ahmadjian e Mason, 1998). Os funcionários transferidos trabalham, então, em projetos específicos para seu empregador temporário. O Shukko não só dá à Hitachi acesso ao estoque de conhecimento tácito fora da organização, como também desenvolve laços sociais entre os funcionários da Hitachi e os de outras empresas. Esses laços, futuramente, incrementam o acesso da empresa ao capital social. A Honda e a Toyota têm trabalhado de modo semelhante com fornecedores para provê-los de conhecimentos-chave. Em troca, esse processo tem freqüentemente levado a fluxos de informação no sentido inverso, beneficiando os dois fabricantes de automóveis e expandindo seu capital social (Choi, 1998; Hartley e Choi, 1996).

É claro que o intenso envolvimento de parceiros-chave com uma empresa é um método eficiente de transferência de pequenos volumes de conhecimento tácito para a companhia. No entanto, mais uma vez esse método tem suas desvantagens. Uma das principais é a possibilidade de que os planos estratégicos da empresa ou o conhecimento relacionado a tecnologias proprietárias seja repassado à concorrência. Isso porque parceiros, como clientes e fornecedores, também relacionam-se com a concorrência da empresa, e ainda porque funcionários podem mudar de emprego. Sendo assim, as empresas devem usar esse mecanismo em áreas nas quais elas possam arcar com os custos de ter um conhecimento proprietário sendo difundido fora da empresa, ou utilizá-lo quando tiverem a certeza de que a informação apreendida pelos parceiros não vai vazar para outras corporações.

\section{Obtenção de grandes volumes de conhecimento explícito}

Grandes volumes de conhecimento explícito são necessários, com mais freqüência, às decisões relativamente estruturadas quando houver alguma certeza de que as relações de causa e efeito são compreendidas. Grandes volumes de informação descritiva muito detalhada estão tornando-se críticos para o alcance de vantagem competitiva em inúmeras indústrias - em particular, informações sobre a cadeia de valor cliente-fornecedor. Quando grandes volumes de conhecimento explícito de instituições externas são necessários, é mais provável que mecanismos de troca eletrônica de informação provemse altamente benéficos. Exemplos de tais tecnologias incluem as conexões que empresas de empréstimo ao consumidor mantêm com agências de crédito como a Experian, ou os vínculos que as agências de viagens online estabeleceram com as companhias aéreas. 
As primeiras formas de compartilhamento dessas informações foram especialmente relatadas nos relacionamentos entre os grandes varejistas e os fornecedores. Os varejistas utilizavam um modo de transferência de informação chamado EDI - Electronic Data Interchange. O EDI é utilizado basicamente para repassar aos fornecedores informações instantâneas sobre os estoques de seus produtos no varejo; no entanto, também é útil para rastrear os hábitos e preferências de compra dos consumidores. Nos últimos anos, novas formas de sistemas de compartilhamento eletrônico de informações como o XML - Extensible Markup Language - colocaram o compartilhamento eletrônico de informações ao alcance até mesmo das pequenas empresas e aumentaram a prevalência da partilha interorganizacional de informações (Galaz e Carlson, 2000).

Várias empresas especializadas disponibilizam ferramentas que ajudam as companhias a fornecer conhecimento explícito. A Arthur Andersen do Reino Unido, por exemplo (sua divisão de consultoria na qual se baseou este exemplo é hoje conhecida como Naviant), contratou recentemente o Navegador Comercial da OneSource para fornecer informações específicas a suas equipes de pesquisa. Esse navegador é um software especializado que fornece informações sobre empresas e indústrias e que é constantemente atualizado e fácil de acessar. Um porta-voz da Arthur Anderson relatou que o uso de informações externas era extremamente importante para seu negócio, e as informações adequadas aumentavam o "valor agregado" do tempo que as equipes gastavam com informações externas ao mesmo tempo em que reduziam o tempo gasto na busca por tais informações (Mason, 2000).

Sistemas de intercâmbio eletrônico de dados são extremamente úteis ao fornecimento de grandes volumes de informação rotineira e facilmente compreensível. No entanto, realmente exigem uma certa uniformidade de linguagem e interpretações entre os emissores e os receptores. Conseqüentemente, esses sistemas não são muito úteis à obtenção de informações não-rotineiras e complexas, que tendem a ser tácitas em sua natureza.

\section{Obtenção de grandes volumes de conhecimento tácito}

No ano passado, percebemos a necessidade de adquirir experiência imediata em capacidades e sistemas de integração de redes. Apesar de tais componentes não fazerem parte das linhas de produtos da NIT, nossos clientes precisavam com freqüência desses serviços. Senti- mos que contar com tal capacitação constituiria um acréscimo à nossa vantagem competitiva. No entanto, levaria muito tempo para adquirir o volume de conhecimento tácito necessário nessa área. Consideramos a aquisição da DEI Systems, especializada na área. Mas, em vez disso, decidimos ingressar em uma aliança estratégica com ela. Com a aliança, evitamos as armadilhas das aquisições: questões regulamentares e logísticas, incompatibilidade cultural etc. A aliança permitiu-nos o acesso a grandes volumes de conhecimento necessário em uma nova área, atendeu melhor a nossos clientes e, é claro, não nos exclui de considerar a aquisição da DEI em um momento futuro... ${ }^{3}$.

A migração entre mercados relacionados, a oferta de novos serviços, a modificação nas bases de concorrência e outras mudanças em grande escala freqüentemente exigem conhecimento tácito substancial em áreas que são relativamente pouco familiares para a empresa. Quando as corporações necessitam de grandes volumes de conhecimento tácito de instituições externas, elas precisam criar estruturas e processos que permitam que o conhecimento seja transferido em múltiplos domínios e para pontos diferentes, além de serem adequados dentro da organização. Tais transferências são melhor executadas mediante agentes de cooperação, como alianças estratégicas.

Uma aliança estratégica é definida como "qualquer acordo de cooperação voluntariamente iniciado entre duas empresas que envolva o intercâmbio, o compartilhamento ou o co-desenvolvimento, e pode abranger contribuições de capital, tecnologia ou bens específicos de uma empresa vindas de parceiros" (Gulati e Singh, 1998). Da perspectiva do compartilhamento de conhecimento, essas alianças podem acontecer de múltiplas formas. A Intel e a Stmicroelectronics, NV (anteriormente, SGS Thomson Microelectronics), por exemplo, são duas empresas que operam em uma indústria volátil, na qual precisam obter grandes quantidades de conhecimento de fora dos limites organizacionais. De modo a otimizar seu acesso ao conhecimento externo, as duas empresas firmaram um acordo, em que ambas podem utilizar as propriedades intelectuais uma da outra, com isenção de custos e sem necessidade de qualquer aprovação prévia da outra parte. (Detalhes sobre esse acordo estão especificados em um comunicado à imprensa disponível em http:// www.intel.com/press/990224.html . A cópia impressa desse comunicado está arquivada com os autores e pode ser fornecida mediante solicitação.)

Alianças como a descrita anteriormente são especialmente importantes para empresas pequenas e recém-inauguradas que estão tentando competir com 
grandes corporações multinacionais já estabelecidas e poderosas, e precisam ter acesso a grandes volumes de conhecimento tácito mediante alianças estratégicas. A Arkia Israel Airlines, por exemplo, era uma pequena empresa aérea estatal em Israel. Foi privatizada em 1980 e, desde então, vem crescendo e competindo com sucesso com grandes companhias aéreas que operam no mundo inteiro. De modo a beneficiar-se do conhecimento necessário para competir globalmente, a companhia aérea firmou alianças estratégicas com uma ampla gama de parceiros, que incluiu diversas autoridades aeroportuárias, agências de viagens e a Swiss Air. Em uma recente entrevista, Israel Borovitch, CEO da Arkia, destacou: "uma aliança estratégica é um excelente modo de adquirir knowhow profissional, bem como conhecimento sobre negócios, legislação e economia, exclusivo dos diferentes ambientes locais. Uma aliança também dá a compreensão e o conhecimento sobre diferentes culturas nas quais as corporações multinacionais operam hoje." (Essa entrevista de Israel Borovitch foi publicada na Academy of Management Executive, v. 15, n. 1, p. 12 5, Feb. 2001.)

Os exemplos ilustrados anteriormente sobre o valor das alianças estratégicas também são corroborados por pesquisas empíricas. Um estudo recente com empresas da indústria de semicondutores constatou que as alianças constituem um dos métodos mais importantes utilizados pelas empresas para o fornecimento de conhecimento (Stuart, 2000). O estudo também concluiu que as empresas que obtêm grandes quantidades de informação por meio de alianças, e escolheram seus parceiros com cuidado, alcançam níveis melhores de desempenho do que as outras corporações.

Sendo assim, existem vários métodos por meio dos quais as empresas podem usufruir o conhecimento externo. No entanto, a adequação de cada método depende do tipo e do volume de conhecimento que está sendo buscado. Conseqüentemente, os gerentes que estão tentando alavancar o capital social de uma empresa precisam determinar primeiro que tipo de conhecimento está sendo buscado e então escolher o método apropriado para obtê-lo.

\section{PREPARANDO UMA ORGANIZAÇÃO PARA O APROVEITAMENTO DO CAPITÁL SOCIAL}

Embora o capital social possa ser extremamente benéfico para uma organização, e ainda que se tenha a impressão de que as empresas beneficiam-se facilmente de suas vantagens, as corporações variam bastante em suas habilidades de aproveitá-lo de modo efetivo. A determinação da natureza do conhecimento externo necessário e a escolha de um método apropriado para obter o conhecimento são apenas o primeiro passo no aproveitamento do capital social: uma organização deve se preparar para receber, absorver e utilizar o conhecimento obtido dessa forma - um processo que envolve várias etapas. Além disso, deve se certificar de que o conhecimento que está sendo obtido é atual e confiável. Na ausência de tal preparo, as empresas podem perder recursos preciosos tentando aproveitar o capital social e, em alguns casos, as organizações chegam até mesmo a perder sua vantagem competitiva ao longo do processo. Delineamos, a seguir, as várias etapas que as empresas devem percorrer para tirar vantagem do capital social com sucesso.

\section{Desenvolver um nível adequado de conhecimento prévio}

Jim concentrou-se em como uma organização poderia alavancar seu capital social. "Depender de um fornecedor externo de conhecimento, em um domínio específico, não significa que a empresa abandone completamente seu conhecimento naquele domínio." Ao preparar esse trecho da palestra, Jim recordou-se do tempo em que a NIT dependia de outra empresa para desenvolver um subcomponente de um de seus produtos. A Ralph Enterprises ocupava reconhecidamente a liderança em seu campo de atuação. Seus funcionários estavam trabalhando sinceramente para transferir seu conhecimento para a NIT, mas o processo estava emperrado. Os engenheiros de design da NIT sentiram que as idéias dos funcionários da Ralph eram muito teóricas e não podiam ser facilmente adaptadas para as especificações de seus produtos. Os funcionários da Ralph, por sua vez, sentiam que os engenheiros de design da NIT não estavam muito ansiosos para aprender os detalhes de sua tecnologia. O problema prolongou-se por vários meses. Finalmente a NIT designou dois novos engenheiros, que tinham conhecimento sobre as tecnologias da Ralph para a equipe de design de produto. Eles não eram especialistas; entretanto, sua familiaridade com a tecnologia básica da Ralph e com os produtos da NIT permitiu que eles traduzissem o conhecimento da Ralph em uma forma que pudesse ser utilizada pelo resto da equipe.

A capacidade de absorção refere-se à habilidade de uma organização para compreender o novo conhecimento localizado do lado de fora de seus limites, assimilá-lo 
com seu estoque atual de conhecimento e utilizá-lo em suas operações (Cohen e Levinthal, 1990). Para que a organização tenha capacidade de absorver novo conhecimento, deve contar com um certo nível de conhecimento prévio relacionado. Além disso, a organização precisa contar com processos que facilitem o uso de tal conhecimento. Considere, por exemplo, uma empresa de produtos eletrônicos para consumo. Ela pode ter acesso ao conhecimento mais recente em tecnologia digital, mas, a menos que seus funcionários tenham algum conhecimento básico sobre tecnologia digital, ela não vai ser capaz de tirar vantagem do acesso que possui.

Conseqüentemente, se uma empresa depende de pessoas de fora para obter conhecimento em um determinado domínio, ela não pode interromper completamente o treinamento de seus próprios funcionários naquela área. A menos que mantenha um nível básico de experiência nos domínios relevantes de conhecimento, ela não vai ser capaz de se beneficiar de seu capital social. No início da década de 1980, por exemplo, a Sony Corporation parou de desenvolver suas experiências em tecnologia digital e em outras tecnologias relacionadas porque não acreditava que pudesse tornar-se um líder nessa área. Vários anos depois, no entanto, decidiu que precisava ganhar experiência naquele domínio para desenvolver seu negócio de produtos eletrônicos para consumo. Como a Sony havia negligenciado a manutenção atualizada de seu conhecimento na área, teve de despender recursos consideráveis para desenvolver internamente os níveis de conhecimento (Nathan, 1999). Uma vez concluído o processo, a Sony firmou alianças estratégicas (com a Phillips, por exemplo, no caso dos aparelhos de CD e DVD) para suplementar seu conhecimento no campo.

\section{Combinar o método ao \\ conhecimento que está sendo buscado}

Jim Campbell agora estava pisando em um terreno perigoso - os problemas que a NIT havia enfrentado no processo. Após muita deliberação, decidiu falar sobre Kelly Maynard (o nome é fictício por motivo de confidencialidade), ex-Diretora de Pesquisa da NIT. "Kelly era uma cientista de destaque. Era muito bem conceituada na comunidade científica e nos considerávamos sortudos por tê-la contratado. No entanto, alguns meses após sua contratação, percebemos uma tendência inquietante: ela era fanática por e-mails! Ela possuía excelentes contatos e parecia ser um bom recurso para aproveitamento de capital social. Mas sempre que obtinha ou compartilhava conhecimento era via e-mail. Reuniões face a face eram sempre desencorajadas por con- sumirem muito tempo. Agora, apesar de o e-mail ser ótimo para compartilhar informações que não sejam ambíguas, ele pode ser contraproducente quando utilizado para compartilhar conhecimento mais complicado, que exija discussões entre os funcionários para que seja compreendido. Ao longo daquele período começamos a perceber que o conhecimento obtido de fora era interpretado de modo diferente por diferentes funcionários, levando a mal-entendidos e conflitos. Ficou aparente para nós que boa parte disso poderia ter sido evitada se Kelly tivesse intercalado seus vários e-mails com algumas interações pessoais. Tentamos aconselhála, mas ela não queria mudar. Por fim, tivemos de dispensá-la." - uma situação semelhante foi descrita no artigo de Markus (1994).

Ao usufruir seu capital social, as organizações precisam obter conhecimento por meio da comunicação. Elas podem realizar esse processo mediante inúmeros meios de comunicação, como interação pessoal, telefone, e-mail, fax etc. No entanto, nem todos os meios são equivalentes - a teoria da riqueza dos meios diz que cada meio tem características específicas que podem torná-lo adequado para o acesso a algumas formas de conhecimento, e ineficaz para o acesso a outras formas (Daft e Lengel, 1986).

De acordo com a teoria da riqueza dos meios, certas formas de conhecimento e informações - e especialmente conhecimento tácito - são ambíguas e/ou equívocas em sua natureza. Elas não são facilmente compreendidas, nem é prontamente evidente quais perguntas adicionais precisam ser formuladas para melhorar sua compreensão. A fim de que os gerentes compreendam tal conhecimento, a comunicação entre emissores e receptores deve ser contínua e interativa, e deve permitir a transmissão de múltiplas formas de comunicação - isto é, verbal e não-verbal. Ela também deve permitir debate e repetidas interações para esclarecimentos entre emissores e receptores. Os meios de comunicação que satisfazem os critérios anteriores são chamados de mídia rica. A interação face a face é geralmente considerada um dos meios mais ricos disponíveis.

Por outro lado, podemos encontrar informação que é direta e prontamente compreendida. Em tais casos, pode ser preferível utilizar uma mídia "enxuta", que consome menos recursos ao transferir grandes volumes de dados. Portanto, mídias como EDI são eficientes para o aproveitamento de grandes volumes de conhecimento explícito, mas não são adequadas para o aproveitamento de conhecimento tácito. Outros exemplos de mídia relativamente enxuta incluem o uso de cartas e faxes, enquanto chamadas telefônicas e e-mails 
apresentam nível intermediário de riqueza. É extremamente importante para as organizações a utilização de um meio de comunicação que corresponda ao conhecimento externo que está sendo acessado.

Gerentes sensíveis à mídia são aqueles que escolhem um meio de comunicação que seja adequado ao conhecimento que estão buscando (Trevino, Daft e Lengel, 1990). Nesse contexto, as organizações precisam dar a seus funcionários acesso a múltiplas tecnologias de comunicação. Além disso, os funcionários devem ser treinados na utilização dessas múltiplas tecnologias e sensibilizados para o fato de que algumas delas são mais adequadas do que outras para o fornecimento de tipos específicos de conhecimento.

Como todas as exigências de conhecimento organizacional raramente irão recair em apenas um dos tipos ilustrados na Figura 1, múltiplos modos de comunicação podem ser necessários para que o conhecimento seja fornecido a partir do mesmo agente externo. É altamente improvável, por exemplo, que uma empresa necessite apenas de conhecimento tácito de uma dada fonte. Ela pode precisar de pequenas quantidades de conhecimento tácito e de grandes quantidades de conhecimento explícito. Nesse caso, a melhor forma de usufruir o conhecimento da instituição externa é estabelecer uma conexão EDI e alistar os funcionários da empresa externa como membros de uma equipe de trabalho em atividades relevantes para a organização.

\section{Visão holística do capital social}

Até aqui descrevemos os vínculos da organização com provedores externos de conhecimento, sendo que cada vínculo é discreto e independente. No entanto, na realidade o capital social de uma empresa deve ser visto de modo holístico. Os gerentes precisam traçar o mapa do capital social de uma empresa colocando a organização no centro e mapeando seus vínculos com provedores externos de conhecimento. Esses mapas permitem que os gerentes avaliem se dependem ou não de um conjunto diverso de provedores independentes de conhecimento. Eles também possibilitam aos gerentes comparar os vínculos que suas empresas possuem com instituições externas àqueles firmados por seus concorrentes e examinar a natureza e a força desses vínculos.

Tais mapas têm o poder de gerar idéias úteis para a organização. Os gerentes podem descobrir, por exemplo, após a elaboração de um desses mapas, que todas as fontes de conhecimento da empresa estão expostas a condições ambientais idênticas. Essa situação é problemática. Um recente estudo constatou, por exemplo, que o desempenho dos fabricantes de microchips da região às margens da Rota 66, em Boston, caiu porque eles viram-se entrincheirados na busca de informação junto a instituições localizadas basicamente naquela parte do país e privaram-se de excitantes desenvolvimentos que estavam acontecendo em outros locais (Saxenian, 1994). Por outro lado, os gerentes podem concluir que a empresa tem acesso a grandes quantidades de capital social, mas seus vínculos não são diferentes dos de seus concorrentes. Como todas as empresas do ramo recorrem às mesmas fontes, é improvável que o capital social assegure vantagem competitiva.

Os mapas também servem como guias úteis para permitir aos gerentes administrar melhor o capital social, pois os informam, por exemplo, sobre a estrutura e a natureza do capital social de uma empresa. Assim, os gerentes podem concentrar-se em motivar as instituições com as quais mantêm vínculos para compartilharem conhecimento que possa beneficiar a empresa de modo proativo. Isso é importante porque algumas empresas, apesar de vinculadas às mesmas instituições que seus concorrentes, conquistam maiores benefícios por serem mais competentes para aproveitar conhecimento a partir de suas redes.

A forma pela qual uma entidade externa pode ser motivada para contribuir com conhecimento depende de suas características. Quando o conhecimento é extraído dos contatos sociais dos funcionários, por exemplo, os provedores de conhecimento são motivados por sentimentos de confiança, expectativas de reciprocidade, e pela necessidade de manter a reputação junto a seus pares. No entanto, quando as organizações dependem de seus vínculos formais com outras organizações, elas precisam criar incentivos para tais entidades. A Toyota, por exemplo, foi pioneira em práticas únicas que melhoraram suas habilidades de obter conhecimento a partir de suas redes sociais (Dyer e Nobeoka, 2000). Em primeiro lugar, ela criou organizações regionais de fornecimento que se encontravam a intervalos regulares para compartilhar as melhores práticas. Ela também criou equipes de consultoria compostas de funcionários de diferentes empresas. A qualquer momento que a Toyota ou qualquer uma de suas afiliadas enfrenta um problema-chave, a equipe de consultoria é designada para se dedicar a ele. Garantindo benefícios para toda a rede de parceiros, a Toyota gerou incentivos para seus parceiros compartilharem conhecimento de boa vontade.

Para desenvolver o mapa do capital social para suas próprias organizações, os gerentes precisam examinar os vínculos da empresa com os fornecedores e compreender relacionamentos diversos (como alianças) que 
existem com outras organizações. Os administradores também precisam reconhecer as redes sociais de seus gerentes-chave. O desenvolvimento de tal mapa para a concorrência exige mais esforço. Fontes secundárias de informação podem ser usadas para determinar os vínculos formais da concorrência com outras empresas. Uma análise em segundo plano dos executivos-chave que trabalham para a concorrência pode gerar informações úteis. As redes sociais cruciais do CEO de uma empresa concorrente podem ser determinadas por meio do exame dos membros externos do quadro de uma empresa, bem como por meio da identificação de outras empresas onde o CEO atue como membro.

\section{Controle contínuo da \\ validade e do valor do capital social}

"As pessoas precisam usufruir o capital social com cuidado. Ele não é a cura para todas as moléstias, e às vezes pode agir contra a organização." Jim recordou-se de uma interessante experiência que envolveu a SuperMax Inc. A SuperMax era uma varejista-chave dos produtos da NIT. Ela possuía lojas em todo o país e era considerada próxima aos clientes. Mantendo a política de aproveitamento do capital social, a NIT buscou informações sobre as exigências e características dos clientes junto à SuperMax. No entanto, por algum tempo, a SuperMax afastou-se de seus clientes - perdeu contato com essa importante fonte de sua força organizacional. Ela continuou utilizando sistemas de pesquisa ultrapassados que falharam em identificar a ameaça emergente de uma nova tecnologia de um dos concorrentes da NIT. Isso aconteceu seis meses antes de a NIT perceber que a informação sobre os clientes obtida junto à SuperMax era extremamente falha. Nesse momento, eles decidiram utilizar meios alternativos para obter informações sobre os clientes. No entanto, várias decisões haviam sido tomadas com base em informações fornecidas pela SuperMax, e a NIT passou por um período difícil. Nessa fase, Jim estimou que a NIT havia perdido vários pontos de participação no mercado para seus concorrentes. (Essa história é parcialmente inspirada nos problemas enfrentados pela Singer e pela Sears quando elas dependiam exclusivamente uma da outra para desenvolver e promover máquinas de costura no mercado.)

Um dos perigos do aproveitamento do capital social é que as empresas tornam-se altamente dependentes de agentes externos específicos. Isso pode transformar as empresas em "prisioneiras" de seus vínculos com os provedores de conhecimento. Essas organizações podem continuar obtendo conhecimento de fontes externas, ainda que as condições ambientais já tenham tornado obsoleto o conhecimento de seus parceiros externos (Talmud, 1999).

Vários pesquisadores indicaram que as redes de vínculos das organizações alteram sua natureza ao longo do tempo. A informação advinda do capital social de uma organização pode deixar de ter valor ao longo do tempo e a organização pode não ter a capacidade de desenvolver novos relacionamentos. Isso pode acontecer por várias razões. Em primeiro lugar, se os vínculos já existentes de uma organização tiverem sido úteis e benéficos no passado, há uma enorme pressão sobre os gerentes para que se mantenham tais relacionamentos (Gargiulo e Benassi, 1999 e 2000). A pressão acontece por causa do valor percebido desses vínculos dentro da organização, e também porque os gerentes evitam criar a reputação de "abandonar" fontes que já os atenderam bem no passado. Conseqüentemente, exige-se que os gerentes gastem uma considerável quantidade de tempo e recursos para manter as redes organizacionais que não são realmente benéficas. Isso limita o tempo e os recursos disponíveis para os gerentes buscarem e estabelecerem parcerias mais úteis.

Em segundo lugar, se fontes externas de conhecimento já se provaram muito bem sucedidas no passado, os gerentes que dependem desses recursos desenvolvem uma "inércia relacional". Inércia relacional diz respeito à condição em que os gerentes desenvolvem laços muito fortes com agentes externos e têm menor probabilidade de reconhecer ou dar importância às informações advindas de outras fontes, que põem em cheque o conhecimento e a informação que estão sendo recebidos dos vínculos estabelecidos. Esse estado é especialmente perigoso porque o impacto de receber informação ruim de redes de fontes é normalmente percebido ao longo de um extenso período de tempo. No momento em que os gerentes saem de sua inércia relacional, o dano pode ser muito grande para ser facilmente reparado.

É importante que os gerentes tenham consciência dos revezes do capital social, especialmente quando as desvantagens não são aparentes por um período de tempo. Eles precisam avaliar continuamente seus vínculos com agentes externos e assegurar sua flexibilidade em modificar seu capital social quando surge a necessidade. A discussão anterior também sugere que os gerentes precisam ter consciência do aspecto dinâmico de seu capital social - quando os vínculos são estabelecidos com instituições externas, é provável que não sejam imediatamente compensadores. A empresa precisa ter paciência enquanto ela e seus parceiros desenvolvem certo grau de confiança mútua. Uma vez estabelecida a confiança, e considerando que a rede de 
parceiros compreende as necessidades de cada lado envolvido, o valor do capital social provavelmente irá se constituir. No entanto, se a empresa vem usufruindo fontes específicas de capital social por um período de tempo, ela pode se ver aprisionada em suas relações sociais com outras empresas e seu capital social pode se tornar um risco, em vez de um bem (Uzzi, 1997).

\section{Gerenciando alianças e protegendo o conhecimento crucial interno}

Ainda que o capital social advindo de alianças seja extremamente útil às organizações, uma organização não pode ser completamente dependente dele. Em ambientes de negócios de conhecimento intensivo, a vantagem competitiva é dada à empresa que tem a capacidade de desenvolver para suas atividades um conhecimento raro, valioso e difícil de ser duplicado. Como a empresa não controla o capital social, ele está potencialmente disponível para a concorrência. Assim, a raridade torna-se improvável. Logo, a menos que a empresa possua internamente conhecimento raro e valioso, o capital social sozinho possivelmente não irá prover uma vantagem competitiva sustentável e prolongada. É mais provável, no entanto, que, quando o capital social for usado para suplementar o conhecimento crucial único possuído pela empresa, ele possa melhorar sua posição competitiva.

Além do exposto anteriormente, os pesquisadores têm enfatizado que as empresas que ingressam em alianças sem possuir níveis mínimos de conhecimento crucial dentro de suas fronteiras estão sujeitas a parcerias oportunistas. O oportunismo pode assumir diversas formas: o parceiro pode extrair o conhecimento da empresa e então utilizá-lo para favorecer seus próprios interesses. Ou o parceiro pode ter representado mal as capacidades que agregaria à aliança. Finalmente, o parceiro pode falhar em providenciar o conhecimento prometido à aliança (Hamel, 1991; Dyer, 1997).

Para usufruir efetivamente o conhecimento por meio de alianças estratégicas e para proteger-se das parcerias oportunistas, os pesquisadores identificaram vários passos que podem ser adotados pelas empresas (Hamel, 1990; Gulati e Singh, 1998; Deeds e Hill, 1998; Hignite, 1998). Em primeiro lugar, uma empresa que esteja planejando firmar alianças precisa investigar completamente seu potencial parceiro - tanto em termos do conhecimento que ele possui quanto a seu registro passado de alianças. Em segundo lugar, quando a possibilidade de oportunismo é elevada, a empresa pode proteger seus interesses por meio da escolha de mecanismos adequados de supervisão para controlar a aliança. Tais meca- nismos incluem investimentos equiparados entre os parceiros ou o estabelecimento de joint ventures, nas quais a empresa esteja em posição de supervisionar de perto a aliança. Finalmente, apesar da empresa precisar de paciência a fim de obter os benefícios de uma aliança, ela deve estabelecer claramente, com antecedência, critérios quantificáveis que lhe permitam determinar se a aliança está atendendo ou não a seus propósitos; se necessário, a empresa deve estar disposta a encerrar a aliança.

\section{Determinação precisa das futuras necessidades organizacionais de conhecimento}

A fim de desenvolver seu capital social, as organizações precisam conhecer suas futuras necessidades de conhecimento. Tais necessidades, por sua vez, podem ser categorizadas em conhecimento necessário para apoiar dois conjuntos de atividades: utilização e exploração (March, 1996). Utilização refere-se às atividades organizacionais visadas quando se faz melhorias nos produtos e processos comerciais já existentes. Em geral, as organizações mantêm processos sistemáticos que as ajudam a identificar as necessidades de conhecimento relacionadas à utilização. De fato, o capital social existente pode ser aproveitado para identificar essas necessidades de conhecimento - clientes, associações comerciais, universidades e mesmo dados secundários fornecem idéias que informam as organizações sobre necessidades de conhecimento.

No entanto, nos ambientes comerciais de hoje, as organizações também precisam se concentrar a cada dia mais na exploração: atividades que envolvem a adoção e o desenvolvimento de produtos ou processos revolucionários que rompem com os modos existentes de fazer negócios. Alguns exemplos incluem a emergência, na indústria de viagens, da emissão eletrônica de passagens e a presença de agências de viagens na rede mundial de computadores; a emergência de tecnologia para o download de vídeos no computador, que vem ameaçando a indústria de aluguel de fitas de vídeo; e assim por diante.

As necessidades de conhecimento que apóiam as atividades exploratórias tipicamente não estão disponíveis a partir de fontes tradicionais utilizadas pela indústria e, conseqüentemente, são difíceis de ser antecipadas (Christensen, 1997). No entanto, as organizações podem desenvolver várias ações para facilitar a obtenção de tal conhecimento. Em primeiro lugar, as organizações às vezes precisam estar dispostas a tomar decisões arriscadas, com base na intuição e no discernimento isso está em completa oposição ao foco na racionalidade das décadas passadas. Em segundo lugar, elas precisam promover sessões periódicas de brainstorming. Nessas 
sessões, mesmo as idéias aparentemente inatingíveis devem ser levadas em conta, e deve-se buscar informações para determinar sua validade e aplicabilidade. Finalmente, as organizações precisam definir metas desafiadoras, que não possam ser alcançadas com o conhecimento atualmente disponível para a empresa, a fim de deslanchar a criatividade e os esforços adicionais dos funcionários. Vários pesquisadores indicaram que tais metas motivam os funcionários a buscar extensamente informações e conhecimento novos. Isso favorece, por outro lado, a identificação das futuras necessidades de conhecimento que possam ajudar a enfrentar os desafios emergentes na indústria, ou mesmo gerar mudanças radicais no ambiente de negócios da empresa.

\section{CONCLUSÕES}

Várias semanas haviam se passado desde que Jim Campbell apresentou sua palestra. O grande número de e-mails e cartas que ele havia recebido desde então evidenciava que ele havia sido bem sucedido. Ele estava lendo uma mensagem do CEO de uma grande empresa do Brasil, que lhe escreveu para declarar que havia enfatizado pessoalmente a importância do capital social para todos os funcionários-chave. Em acordo com alguns dos temas que Jim havia discutido, o CEO brasileiro havia encorajado seus funcionários a interagirem com parceiros e investidores e se envolverem mais com associações de indústria. Jim pensou com ironia: "é um bom começo, mas se alguém na concorrência estiver levando essas idéias a sério, é provável que tenhamos de adotar alguns esforços adicionais por aqui". Olhou para o relógio. Estava na hora de ir. Ele havia prometido participar de um almoço que havia sido organizado para um grupo de executivos por um dos principais clientes da NIT. A NIT os havia convidado a uma visita de uma semana para aprender mais sobre os produtos e serviços da empresa... a esperança era que eles desenvolvessem fortes relacionamentos com os funcionários-chave da NIT.

Ingressamos em uma fase mais amadurecida da era da informação. Hoje, o conhecimento é o recurso mais valioso que a maioria das organizações pode possuir. E, dado o papel crítico que o conhecimento exerce para as organizações no século XXI, fica claro que não basta contar com grandes quantidades de conhecimento dentro da organização. A maior parte do conhecimento reside fora dos limites das organizações, de modo que as empresas que forem mais eficientes em localizar e usufruir o capital social serão aquelas que irão conquistar vantagem competitiva.

Existe uma ampla variedade de tipos de conhecimento e mecanismos para sua obtenção e utilização. Neste artigo, analisamos pesquisas empíricas e teóricas em um grande número de áreas, incluindo teoria das redes, teoria da empresa baseada em recursos, teoria da empresa baseada no conhecimento, alianças estratégicas etc. Revisamos muitos dos desafios práticos de administrar tal conhecimento e as alternativas disponíveis para ajudar as empresas a dominar sua colocação em uso efetivo (ver Figura 1). Além disso, as organizações precisam percorrer várias etapas para usufruir efetivamente o capital social. Essas etapas estão destacadas no Quadro 1.

Especificamente, vários métodos para capacitar as organizações a usufruir melhor o capital social são listados, incluindo o uso de múltiplas tecnologias de comunicação, a previsão de futuras necessidades de conhecimento, e assim por diante. Além disso, cada método é posto em prática por meio do uso de diversas ações de apoio. Por exemplo, o desenvolvimento da capacidade de absorção da organização é alcançado mediante ações em etapas, como a manutenção de experiência interna adequada nos domínios em que a organização deseja obter conhecimento, a instilação nos funcionários da importância do conhecimento externo e o estabelecimento de rotinas que facilitem armazenamento e uso de conhecimento de fora da empresa. Tais esforços devem equipar melhor a empresa para não só começar a melhorar sua capacidade de administrar o conhecimento externo atualmente disponível, mas também mantêlo e incrementá-lo ao longo do tempo. Juntos, tais métodos e ações de apoio podem ajudar a estabelecer uma base sólida para a abordagem efetiva de administração do conhecimento, incorporando a poderosa contribuição do capital social de uma empresa.

Concluindo, as organizações que esperam conquistar vantagem competitiva devem desenvolver seu pessoal e seus processos para identificar, acessar, comunicar, criar e, por outro lado, administrar efetivamente o conhecimento localizado fora da empresa. O conhecimento tornou-se, na verdade, o recurso central da era da informação, mas nenhuma empresa pode possuir de modo permanente todo o conhecimento de que precisa dentro de seus limites fronteiriços. Conseqüentemente, tomar ciência do conhecimento, especialmente sobre como obtêlo e administrá-lo, tornou-se, talvez, o elemento mais crítico do sucesso organizacional em longo prazo.

Texto traduzido por Silvia Paes.

Artigo convidado. Aprovado em 02/07/2002. 
Quadro 1 - Preparando uma organização para tirar proveito do capital social

\section{MÉTODO \\ Desenvolvimento da capacidade} de absorção

Desenvolvimento e utilização de múltiplas tecnologias de comunicação apropriadas

Visão holística do capital social

Monitoração da validade do capital social

Proteção e desenvolvimento de conhecimento interno crucial que não seja comumente dominado

Previsão das necessidades futuras de conhecimento

\section{AÇÕES}

- Manutenção de níveis aceitáveis de experiência nos domínios em que a organização pretende usufruir o conhecimento externo.

- Instilação da importância do conhecimento externo nos funcionários.

- Estabelecimento de rotinas que permitam que o conhecimento externo seja armazenado e utilizado na organização.

- Disponibilização de múltiplas tecnologias de comunicação aos funcionários e treinamento dos mesmos para utilização adequada dessas tecnologias.

- Sensibilização dos funcionários sobre a necessidade de utilizar tecnologia de comunicação que seja adequada à informação que se está buscando.

- Comparação dos vínculos sociais da organização com os da concorrência. Garantia de que a empresa possua vínculos únicos com os provedores de conhecimento, diferentes dos mantidos pela concorrência.

- Elaboração de mecanismos que motivem os provedores externos de conhecimento para o fornecerem à organização.

- A vinculação a provedores externos de conhecimento não é suficiente. A empresa deve administrar o capital social e, em particular, motivar esses provedores a compartilharem conhecimento-chave.

- Monitoração contínua das fontes externas que fornecem conhecimento à organização, de modo a assegurar que elas estejam fornecendo conhecimento corrente e atualizado.

- Conscientização de que as organizações podem se ver presas a relacionamentos sociais que já foram úteis, e continuar confiando neles, mesmo quando o conhecimento que eles fornecem não é mais válido.

- Garantia da presença de conhecimento único e de valor, em alguns aspectos-chave das operações da organização, que Ihe dá vantagem competitiva.

- Proteção contra comportamentos oportunistas por parte de parceiros.

- Investimento contínuo de esforços para determinar as futuras necessidades de conhecimento para a empresa. Conscientização de que os esforços de rotina, no que se refere a essa questão, provavelmente não irão informar sobre as necessidades de conhecimento em caso de rupturas na indústria, o que está se tornando a cada dia mais comum nos ambientes de negócios de hoje.

\section{Notas}

Os autores gostariam de agradecer a Akshay Kumar pelos prestimosos comentários sobre as versões iniciais deste artigo.

Artigo publicado originalmente na Academy Management Executive V. 16, n. 1, p. 87-101, February 2002.

Copyright 2002 Academy of Management. Todos os direitos são reservados. Nenhuma parte deste artigo pode ser reproduzida por qualquer meio ou forma sem permissão por escrito da Academy of Management. Para obter permissão, entre em contato com Copyright Clearance Center: www.copyright.com.

1. Jim Campbell e sua empresa NIT são fictícios, mas suas experiências baseiam-se em exemplos da vida real que foram ou relatados na imprensa especializada ou descritos aos autores por profissionais da área.
2. Utilizamos o termo "capital social" para nos referirmos ao que Nahapiet e Ghoshal (Academy of Management Review, 1998) chamaram de "aspecto cognitivo do capital social". Esse aspecto concentra-se no conteúdo do conhecimento que os indivíduos ou as organizações acessam a partir do uso de suas redes sociais. Trata-se de um uso limitado do termo e não nos concentramos nos dois outros aspectos do capital social que Nahapiet e Ghoshal julgaram importante: o aspecto Estrutural, que aborda a extensão dos vínculos sociais que os indivíduos ou as organizações mantêm com entidades externas, e o aspecto Relacional, que avalia a natureza de tais vínculos (se a intensidade é forte ou fraca, se o vínculo é bidirecional ou não etc.).

3. A história baseia-se em um problema semelhante enfrentado pela Safeco Insurance, quando esta tentou desenvolver suas capacidades em seguro para pane em maquinário. Apesar de inicialmente ter considerado a idéia de comprar a Hartford Steam Boiler, especializada nessa área, a empresa finalmente firmou uma aliança estratégica. A história foi relatada no artigo "Choosing partners", publicado na Best's Review (v. 101, n. 11, p. 39-44). 